\title{
Parsiyel anormal pulmoner venöz dönüş anomalisi ile intakt atrial septum birlikteliği: Nadir bir konjenital anomali
}

\author{
Partial anomalous pulmonary venous return with intact atrial septum: A rare \\ congenital anomaly \\ Onur IŞIK ${ }^{1}$ Tolga BAŞ ${ }^{2} \quad$ Murat KOÇ $^{2} \quad$ Hakan AYDIN $^{2} \quad$ Ali KUTSAL $^{2}$ \\ ${ }^{1}$ Ege Üniversitesi Tıp Fakültesi, Kalp Damar Cerrahisi Anabilim Dalı, İzmir, Türkiye \\ ${ }^{2}$ Dr.Sami Ulus Kadın Doğum Çocuk Sağlığı ve Hastalıkları Eğitim ve Araştırma Hastanesi, Kalp \\ Damar Cerrahisi Kliniği, Ankara, Türkiye
}

\section{Öz}

İntakt atriyal septumlu parsiyel anormal pulmoner venöz dönüş anomalisi çocuk yaş grubunda genellikle asemptomatiktir. Çoğu zaman elimizdeki rutin tanı araçları olan EKG, telekardiyografi, ekokardiyografi hatta kateter anjiyografi ile tanınması zordur. Kliniğimizde tanı alan ve cerrahi olarak tedavi edilen hastamızı anomalinin karakteristikleri, klinik gidiş, tanı araçları ve cerrahi tedavi statejileri yönlerinden tartıştık.

Anahtar Sözcükler: Histeroskopi, uterin rüptür, endometrial polip.

\begin{abstract}
Partial anomalous pulmonary venous return with intact atrial septum anomaly is usually asymtomatic in pediatric population. Diagnose of this anomaly can be challenging with our routine eveluation methods like ECG, telecardiography, echocardiography and even catheter angiography. We discussed the anomalous characteristics, clinical progression, and diagnostic methods and surgical strategies employed for a patient diagnosed and undergoing surgical treatment in our clinico.
\end{abstract}

Keywords: Hysteroscopy, uterine rupture, endometrial polyp.

\section{Giriş}

Atriyal septal defekt (ASD) tiplerinden yüksek yerleşimi olan grup ile anormal pulmoner venöz dönüş birlikteliği nadir olmayan bir kardiyak anomalidir. Yüksek yerleşimli ASD bulunan hastaların yaklaşık \%10'unda bir veya daha fazla pulmoner venin (sıklıkla sağ üst pulmoner ven) anormal açıımı görülür (1). Fakat interatriyal ilişkinin olmadığı durumlarda anormal pulmoner venöz dönüş nadir rastlanan bir durumdur. Biz kliniğimizde parsiyel anormal venöz dönüş tanısı alan intakt atriyal septumlu olgumuzu tanı ve tedavi süreci açısından tartıştık.

\section{Olgu Sunumu}

On yaşındaki çocuk hasta çarpıntı ve eforla nefes darlığı şikayetleriyle kliniğimize başvurdu. Fizik muayenesi olağan olan hastanın kardiyak incelemesi sonrası kardiyo-torasik oran normal, EKG normal sinus ritmi, oskültasyonda pulmoner odakta $2 / 6$ sistolik üfürüm ve S2 sabit çiftleşmesi saptandı.

Yazışma Adresi: Onur IŞıK

Ege Üniversitesi Tıp Fakültesi, Kalp Damar Cerrahisi Anabilim Dalı, İzmir, Türkiye

Makalenin Geliş Tarihi: 03.03.2014

Kabul Tarihi: 09.04.2014
Yapılan transtorasik ekokardiyografi (TTE) sonucu sağ pulmoner venlerin döküldüğü alan ile ilgili şüpheler olması nedeniyle transözefagial ekokardiyografi (TEE) planlandı. TEE sonrası da net görüntü elde edilemeyen hastada kateter anjiyografi tetkiki planlandı. Kateter anjiografi girişiminde süperiyor vena kava (SVC) sağ atriyum bileşkesine açılan sağ taraf pulmoner venler kateter ile lümenlerine girilerek yapılan enjeksiyon sonrası görüntülendi, pulmoner/sistemik akımlar oranı 2.12 olarak hesaplandı ancak interatriyal seviyede geçiş görülmedi. Pediyatrik kalp cerrahisi ve kardiyoloji konseyinde tartışılması sonrası tam düzeltim ameliyatına karar verildi. Hasta ve yakınlarının yazılı onamı alındıktan sonra planlanan ameliyat genel anestezi altında median sternotomi, aorta-selektif bikaval kanülasyon sonrası kardiyopulmoner bypass ile başlatıldı. Orta dereceli hipotermi altında topikal soğuk, antegrad kristalloid kardiyopleji uygulaması ile diyastolik arrest sağlandı. Sağ atriyotomiden sağ pulmoner venlerin sağ atriyum süperiyor vena kava bileşkesine döküldüğü ve atriyal septumun intakt olduğu görüldü. Atriyal septektomi yapılması sonrası otolog perikardiyal yama kullanılarak anormal açılımlı pulmoner venler oluşturulan defektten sol atriyuma yönlendirilerek onarım 
yapıldı (Şekil-1a,b,c). Uygun hava çıkarma işlemini takiben sağ atriyotomi insizyonu primer kapatıldı. Normotermi sağlanması sonrası normal sinus ritminde kardiyopulmoner bypass'tan çıkıldı. Hasta sorunsuz yoğun bakım izlemini takiben postoperatif 5. günde taburcu edildi.
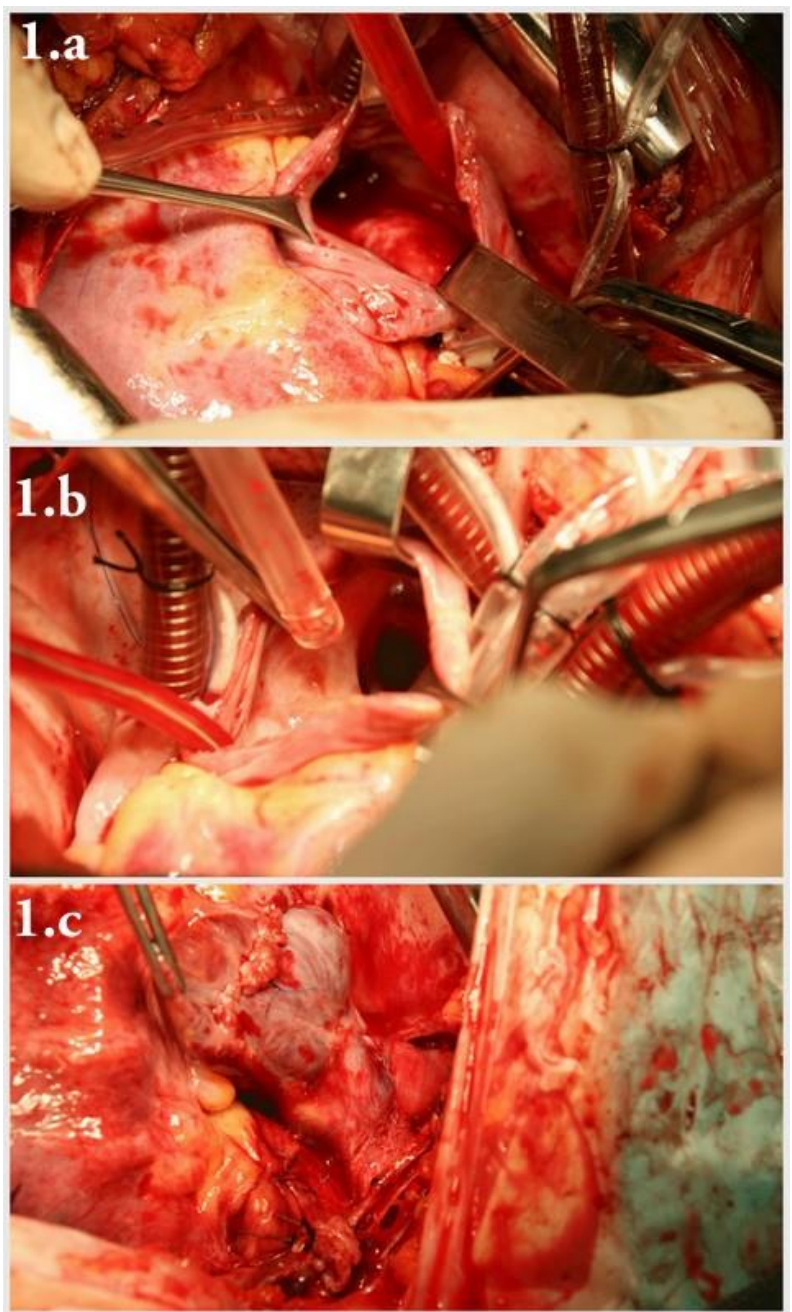

Şekil-1a,b,c. Otolog perikardiyal yama kullanılarak anorma pulmoner ven orifisinin atriyal septektomiye yönlendirilmesi.

\section{Tartışma}

Embriyonik hayatta foregut bir parçasından gelişen akciğerlerin pulmoner venleri sistemik venöz dönüşü sağlayan splanik pleksusa dökülürler. Daha sonra kalbin sol atriumuna dökülecek venler ayrılır. Bu ayrımdaki kısmi başarısızlık sol atriuma dökülecek venlerin sistemik venöz dolaşıma dökülmesinin devam etmesiyle sonuçlanır (1).

Parsiyel anormal pulmoner venöz dönüş (PAPVD) anomalisinin en sık paterni sağ akciğer orta ve üst loblarının sağ SVC-sağ atriyum bileşkesine dökülmesidir (2). PAPVD'nın sağ pulmoner venlerin sağ atriuma döküldüğü paterni en sık 2.; sol pulmoner venlerin vertikal venle innominate vene döküldüğü patern ise 3 . sırayı alır (3). Parsiyel anormal pulmoner venöz dönüş anomalisi \%0.6-0.7 sıklıkta erişkin otopsi serilerinde daha seyrek olarak da klinik serilerde bildirilmiştir (3). Sinüs venozus tip ASD ile PAPVD birlikteliği sık görülmesine rağmen PAPVD intakt atrial septum birlikteliği nadirdir (2)

$\mathrm{Bu}$ hastalar normal büyüme eğrisine sahip olmakla birlikte minimal çarpıntı veya nefes darlığı semptomlarını gösterebilirler. PAPVD intakt atriyal septum fizik muayene bulguları sekundum ASD ile çok benzerlik gösterir. Oskültasyonda sabit çiftleşen S2, normal prekordiyal vuru, EKG'de bazen bifasiküler blok, akciğer filminde minimal parankimal belirginleşme normale yakın kardiyotorasik oran benzeşen bulgulardır.

PAPVD intakt atriyal septum kateter anjiyografi sırasında tanınması zor bir olgudur. Özellikle küçük sol sağ şant olan vakalarda tanı konması daha da zorlaşır. Büyük sol sağ şant var ise eldeki veriler atriyal septal defekt tanısını destekler tarzdadır. Kateter sırasında yapılan oksijen saturasyonu ölçümleri genellikle yol göstericidir. Ana pumoner arter enjeksiyonunun tanıya faydası yokken; selektif pulmoner (sağ ve sol olarak) anjiografide opak maddenin seyri, kateter ile atrial septumdan geçilememesi tanı koydurur. Atriyal septumun kateter ile geçilemediği durumlarda sağ ve sol atriyum arası belirgin basınç farkı durumu destekler. Sağ atriyumda değişik bölgelerden yapılan oksijen saturasyonu ölçümleri (SVC, inferiyor vena kava, atriyum lateral duvarı) anormal dönüşün lokalizasyonu hakkında fikir verirken kateter ile anormal vene direk girilerek gösterilmesi de mümkündür $(3,4)$.

PAPVD intakt atriyal septum birlikteliğinde pulmoner vasküler rezistans yükselmesi konusu yazarlar arasında tartışma konusudur. Bazıları anormal seyirli venin her zaman darlık sorunu olduğunu öne sürerken diğerleri venin döküldüğü atriyum arası basınç farkından dolayı sol tarafa dökülen venin daha rahat açıldığını savunur. Fakat bu değerin yaklaşık aynı olduğu vaka genelinde söylenebilir (5).

PAPVD intakt atriyal septum operasyon kriteri hakkında yazarlar $Q p / Q s$ oranın 2 üzerinde olması gerektiğini bildirir (6). Tek bir pulmoner venin anormal açılımı hemodinamik olarak inmal edilebilir durumdadır. Bu hastalar ameliyat edilmeden izlenebilirler.

PAPVD intakt atriyal septum cerrahi tedavisinde atrial septektomi sonrası anormal ven bağlantısının yönlendirilmesi için kullanılan farklı operasyon teknikleri kullanılmaktadır. Warden tekniği, çift yama tekniği, tek yama tekniği, interatriyal baffle tekniği bunlardan bazılarıdır. Anormal venlerin çok yüksek açılımının olmaması, onarımda SVC lümeninden kayıp olmaması nedeniyle interatriyal baffle tekniğinin uygun onarımı sağlayacağını düşündük. Anormal pulmoner venlerin SVC proksimaline açıldığı vakalarda Warden tekniği, çift 
yama veya transkaval insizyon ile tek yama teknikleri kullanılabilir (7).

$\mathrm{Bu}$ patolojinin tanısının konması zor olmasına karşın cerrahi tedavisi iyi bilinmektedir. Hastalığın tanınmasında TTE, TEE yeterli olabilirken şüphenin devam ettiği hastalarda kateter anjiyografi ile saturasyon, basınç ölçümleri ve anormal ven lümenine yapılan direk enjeksiyonlar yol göstericidir. Cerrahi tedavide azami dikkat gösterilmesi gereken unsurlar; septektomide oluşturulan ASD'nin boyutlarının darlık yaratmayacak kadar geniş olması ve interatriyal septum sınırları içerinde kalması, SVC lümeni ve pulmoner ven ağızlarında darlık oluşturmayacak genişlikte yama boyutu seçilmesi ve sütur hattını mümkün olduğunca sinüs nodundan uzak tutulmasıdır.

\section{Kaynaklar}

1. Hijii T, Fukushige J, Hara T. Diagnosis and management of partial anomalous pulmonary venous connection. A review of 28 pediatric cases. Cardiology 1998;89(2):148-51

2. Fish FA, Davies J, Graham TP Jr. Unique variant of partial anomalous pulmonary venous connection with intact atrial septum. Pediatr Cardiol 1991;12(3):177-80.

3. Alpert JS, Dexter L, Vieweg WV, Haynes FW, Dalen JE. Anomalous pulmonary venous return with intact atrial septum diagnosis and pathophysiology. Circulation 1977;56(5):870-5.

4. AboulHosn JA, Criley JM, Stringer WW. Partial anomalous pulmomary venous return case report and review of the literature. Catheter Cardiovasc Intervent 2003;58(4):548-52.

5. Alsoufi B, Cai S, Van Arsdell GS, Williams WG, Caldarone CA, Coles JG. Outcomes after surgical treatment of children with partial anomalous pulmonary venous connection. Ann Thorac Surg 2007;84(6):2020-6.

6. Stewart JR, Schaff HV, Fortuin NJ, Brawley RK. Partial anomalous pulmonary venous return with intact atrial septum. Thorax 1983;38(11):859-62.

7. Atik E, Bhering MA, Assad RS. Partial anomalous return of four pulmonary veins with intact interatrial septum defect: A rare case report. Arq Bras Cardiol 2007;91(1):e1-3. 